Anais da 3a Semana de Engenharia Civil da

Universidade Federal do Sul e Sudeste do Pará Jan 2020 - v. 2 - n. 1

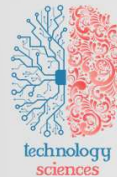

ISSN: 2674-6425

This article is also available online at: www.sapientiae.com.br

\title{
Redução da amplitude térmica por meio de tecnologia verde: estudo de caso no inverno de São Carlos/SP
}

A intensificação da densificação urbana vem produzindo uma concentração de edifícios nos centros urbanos que têm aumentado a incidência de impacto ambientais negativos, os quais afetam tanto no microclima urbano quanto nas temperaturas internas das habitações. A vegetação é um indicativo de qualidade ambiental do ambiente construído devido as inúmeras propriedades que auxiliam na redução dos efeitos negativos da densificação nas urbes. $\mathrm{O}$ uso de vegetação na arquitetura é uma técnica capaz de proporcionar benefícios térmicos fomentando ambientes internos mais agradáveis e com maior eficiência energética. Considerando isso, esse trabalho objetiva analisar e delimitar os benefícios térmicos que os sistemas vegetais podem oferecer aos ambientes internos. Para isso, foi realizado um estudo experimental com o intuito de compreender o comportamento térmico de quatro células de teste: um protótipo sem vegetação e três protótipos com diferentes combinações nas coberturas e fachadas, instalados numa região de clima tropical, na cidade de São Carlos-SP. Com base nos registros das temperaturas superficiais internas e da temperatura interna do ar foi possível obter a diferença de temperatura entre as células de teste $\left(2,5^{\circ} \mathrm{C}\right)$ e mensura capacidade da vegetação de isolar termicamente. Os resultados apontam que as células que apresentam vegetação possuem amplitudes térmicas menores, o que significa um comportamento mais constante e temperaturas mais atenuadas.

Palavras-chave: Comportamento térmico; Bioarquitetura; Coberturas verdes; Fachadas verdes.

\section{Thermal amplitude reduction through green technology: case report in the winter in São Carlos/SP}

\begin{abstract}
The enhancement of urban densification has produced a concentration of buildings in urban centers that have increased the incidence of negative environmenta impacts, affecting both the urban microclimate and internal housing temperatures. Vegetation is indicative of the environmental quality of a built environment due to the numerous properties that help reduce the negative effects of densification in urban areas. The use of vegetation in architecture is a technique capable of providing thermal benefits by fostering more pleasant and energy-efficient indoor environments. With this in mind, the present assessment aimed to analyze and delimit the thermal benefits that plant systems can offer to indoor environments. Therefore, an experimental study was carried out to understand the therma behavior of four test cells: a prototype without vegetation and three prototypes with different combinations on the roofs and facades, installed in a tropical climate region, in the city of São Carlos-SP, Brazil. Based on the records of the internal surface temperatures and internal air temperature, it was possible to obtain the temperature difference between the test cells $\left(2.5^{\circ} \mathrm{C}\right)$ and measure the thermal insulation capacity of the vegetation. The results show that cells including vegetation have lower thermal amplitudes, thus denoting more constant behavior and more attenuated temperatures.
\end{abstract}

Keywords: Thermal behavior; Bioarchitecture; Green roof; Green facades.

Topic: Arquitetura e Urbanismo

Reviewed anonymously in the process of blind peer
Received: 08/11/2019

Approved: 21/12/2019
Nuria Pérez Gallardo (iD

Universidade Federal do Sul e do Sudeste do Pará, Brasil http://lattes.cnpq.br/8695660515236363

http://orcid.org/0000-0001-7941-7367

nuria_perez@unifesspa.edu.br

Antonio Carlos Nascimento Passos de Oliveira (id

Universidade Federal do Sul e do Sudeste do Pará, Brasil

http://lattes.cnpq.br/6722503859790070

http://orcid.org/0000-0001-8284-0801

profnascimento@unifesspa.edu.br

\section{Alan Monteiro Borges (iD}

Universidade Federal do Sul e do Sudeste do Pará, Brasil

http://lattes.cnpq.br/3697783631620731

http://orcid.org/0000-0002-1412-961X

alan@unifesspa.edu.br
Flaviany Luise Nogueira de Sousa (iD

Universidade Federal do Sul e do Sudeste do Pará, Brasil

http://lattes.cnpq.br/8912254813326716

http://orcid.org/0000-0003-4527-2811

flaviany.luise@unifesspa.edu.br

Stéfane Mireles da Silva Costa (iD)

Universidade Federal do Sul e do Sudeste do Pará, Brasil

http://lattes.cnpq.br/7998042015741481

http://orcid.org/0000-0001-5915-2672

stefanemireles@unifesspa.edu.br
Referencing this:

GALLARDO, N. P.; OLIVEIRA, A. C. N. P.; BORGES, A. M.; SOUSA, F. L. N.; COSTA, S. M. S.. Redução da amplitude térmica por meio de tecnologia verde: estudo de caso no inverno de São Carlos/SP. Technology Science, v.2, n.1, p.73-78, 2020. DOI: http://doi.org/10.6008/CBPC2674-6425.2020.001.0013 


\section{INTRODUÇÃO}

Segundo Dinsdale et al. (2006) a existência de inúmeros registros históricos revela que o uso de vegetação nas edificações é uma técnica muito antiga, já usada pelo Zigurats da Antiga Mesopotâmia (600 a.C.), devido ao rendimento térmico que esta proporciona. Segundo esses autores, figura como exemplo disto, os jardins de Babilônia localizados no rio Eufrates, os quais foram construídos durante o reinado de Nabucodonosor, que ordenou essa construção com o objetivo de simular uma montanha artificial para encantar a sua esposa, a qual tinha nascido e crescido em um lugar montanhoso ao Norte do país. Prosseguem esses autores informando que, nas escadas das pirâmides, existiam diferentes espécies de árvores e arbustos como proteção a radiação solar. Esse é um dos primeiros exemplos dos primeiros jardins em espaços edificados pelo homem e uma das sete maravilhas do mundo, a qual cobria uma superfície de $200 m^{2}$ de vegetação (DINSDALE et al., 2006).

Atualmente, segundo Zakia (2004), a escassez de vegetação nos centros urbanos, juntamente aos materiais que são utilizados nos processos de urbanização, tem alterado significativamente o clima urbano devido à incidência direta da radiação solar nas construções, transformando as cidades em estufas, fenômeno que, nas últimas décadas, tem gerado um aumento no consumo de energia para resfriamento de ambientes internos.

Desta forma, a vegetação pode ser uma alternativa para a regulação da temperatura devido as inúmeras propriedades que apresenta. Dentre seus benefícios, favorece o ambiente urbano reduzindo ilhas de calor e mitigando as consequências negativas das ações do ser humano nas atividades que realiza no cotidiano. Além disto, atenua as temperaturas internas dos edifícios, as quais são influenciadas pelas características do espaço urbano e o clima do local.

Desde o final do século XX, a construção verde tem ganhado grande popularidade em vários países europeus. Peck et al. (1999) afirmou que Suíça, Holanda, Hungria, Suécia e Grã-Bretanha fomentam o uso de vegetação em edificações, assim como a cidade de Linz em Áustria, na qual o governo municipal retribui aos construtores que projetem com essa metodologia construtiva. Na Suíça, existe uma lei federal sobre tetos verdes e, na Inglaterra, apesar de ter começado lentamente, as políticas sobre esse tema tem ganhado muita e importância na última década, especialmente em Londres e Sheffield (DUNNETT et al., 2008a).

E válido frisar o efeito estético e de amenidade visual que a vegetação pode causar nos habitantes (NICODEMO, 2009), assim a vegetação pode estar ligada inclusive a benefícios biopsíquicos, o que deveria incentivar uma retomada dos projetos urbanísticos que priorizassem a vegetação nas cidades. Dentro desse contexto, o presente trabalho teve como objetivo apresentar o comportamento térmico de quatro células de teste, instaladas em uma cidade de clima tropical, em um dia de inverno para demostrar como a vegetação é capaz de atenuar as temperaturas deixando os ambientes internos mais confortáveis desde um ponto de vista térmico. Para isso, serão considerados parâmetros como a temperatura do ar externo e a temperatura superficial interna dos fechamentos, com o intuito de conhecer a amplitude térmica média, a qual é definida como a diferença entre as temperaturas medias máximas e mínimas (ABNT, 2003). 


\section{METODOLOGIA}

O presente estudo foi desenvolvido no Centro de Recursos Hídricos e Estudos Ambientais (CHREA), localizado em Itirapina-SP (Figura 1), e que pertencente a Escola de Engenharia de São Carlos (EESC), da Universidade de São Paulo (Campus São Carlos) como parte da tese de doutorado da autora principal deste trabalho.

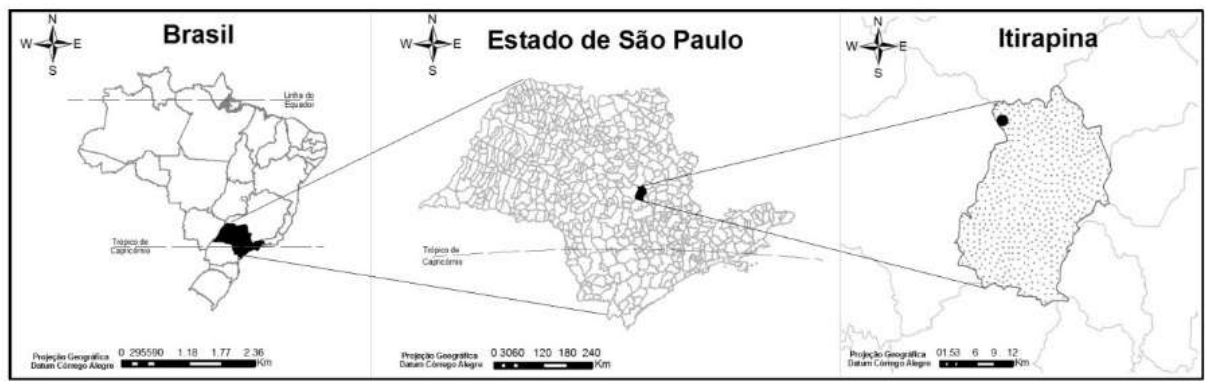

Figura 1: Localização da área de estudo. Centro de Recursos Hídricos e estudos ambientais (CRHEA/USP). Fonte: Gallardo (2017).

Foram construídas quatro células de teste, de dimensões $2,20 \times 2,60 \times 2,90 \mathrm{~m}$, com a mesma orientação, de maneira que, recebem por igual a radiação solar, vento ou qualquer evento atmosférico, a fim de que as condições climáticas atuem simultaneamente e com a mesma intensidade. Nelas se estabeleceram coberturas e fachadas verdes da seguinte forma: Célula 1 - Controle, sem vegetação (CC); Célula 2 - Fachadas verdes (FV) (Norte e Oeste, sendo aquelas que mais hora de radiação solar recebem ao longo do dia); Célula 3 - Cobertura verde (CV) e Célula 4 - Cobertura verde e Fachadas verdes (CVFV) (Norte e Oeste), como mostra a (Figura 2 e Figura 3).

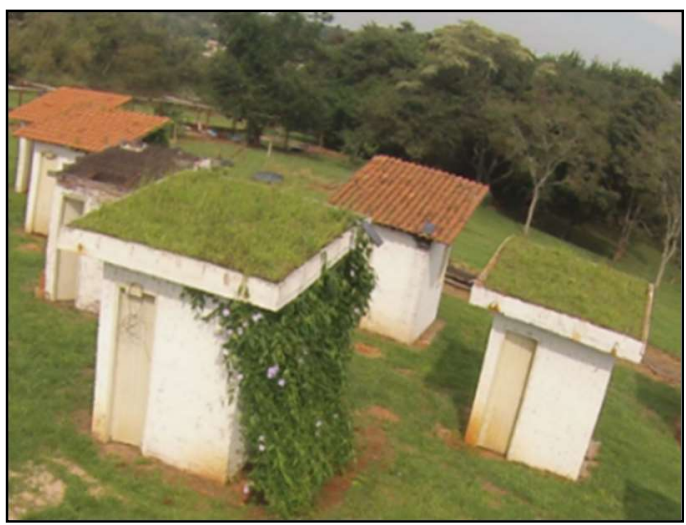

Figura 2: Células de teste detalhe coberturas. Fonte: Gallardo (2017).

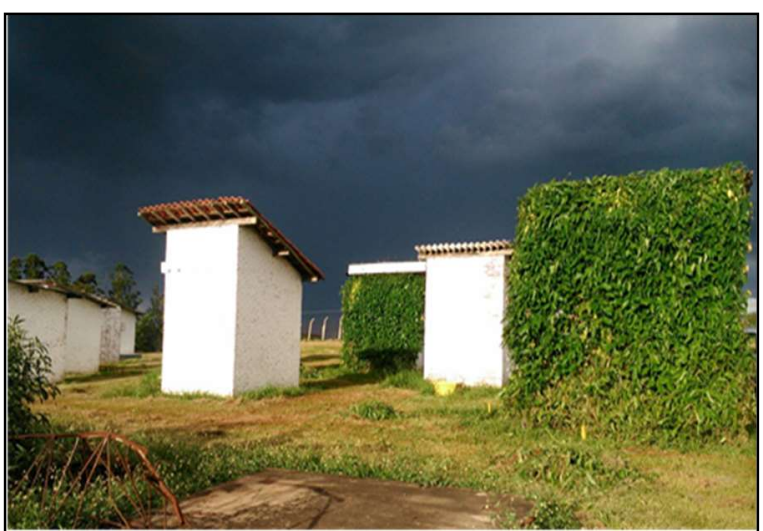

Figura 3: Células de teste: detalhe fachadas.

Fonte: Gallardo (2017).

Os dados de temperaturas internas [Temperatura do Bulbo Seco (TBS) e Temperaturas Superficiais (TSI)] foram mensurados com termopares instalados nas fachadas Norte e Oeste e nas coberturas, em virtude de ser as superfícies que mais radiação solar recebem durante o dia. O registro foi realizado mediante um Datalogger durante um ano completo. A figura 4 mostra a disposição espacial dos termopares responsáveis pelas medições de temperaturas internas (TBS e TSI). 


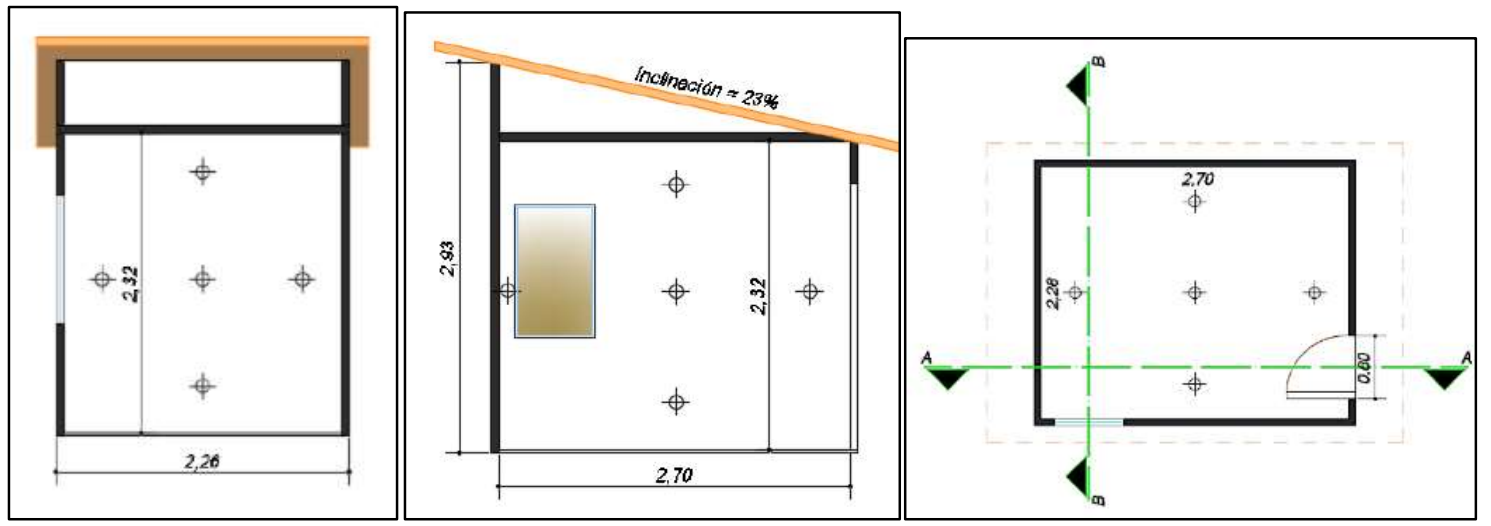

Figura 4: Disposição espacial dos termopares. Fonte: Gallardo (2017).

Enquanto, os dados de temperatura externa, radiação solar e demais variáveis climáticas foram registradas na Estação Meteorologia Automática do CHREA (EESC-USP).

\section{RESULTADOS E DISCUSSÃO}

Os dados climáticos externos (temperatura externa do ar, radiação solar e Umidade relativa do ar) para o dia 4 de setembro, são apresentados na Figura 5 A, B e C. $O$ gráfico presente na Figura 5 A representa a temperatura externa do ar durante o dia de estudo, pode-se perceber que a temperatura máxima registrada foi de $28,3^{\circ} \mathrm{C}$ e a temperatura mínima de $12^{\circ} \mathrm{C}$. O gráfico da Figura $5 \mathrm{~B}$ mostra a umidade relativa do ar, que atingiu seu valor máximo de $96.1 \%$ nos horários de temperaturas mínimas, enquanto o seu valor mínimo foi de $40 \%$, durante as horas de temperaturas mais elevadas. Por fim, o gráfico da Figura $5 \mathrm{C}$ apresenta a radiação solar, no qual é possível perceber, pelo comportamento da curva, a presença de nuvens. O valor máximo de radiação solar registrado foi de $700 \mathrm{~W} / \mathrm{m}^{2}$, no mesmo horário que foi registrada a temperatura mais alta $(13: 00 \mathrm{~h})$.

A

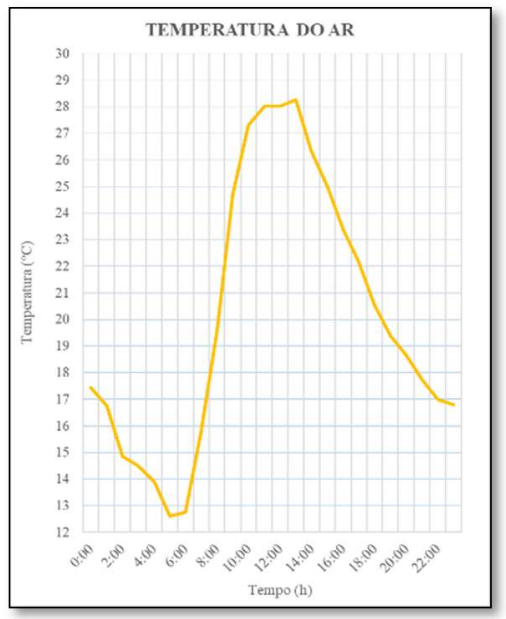

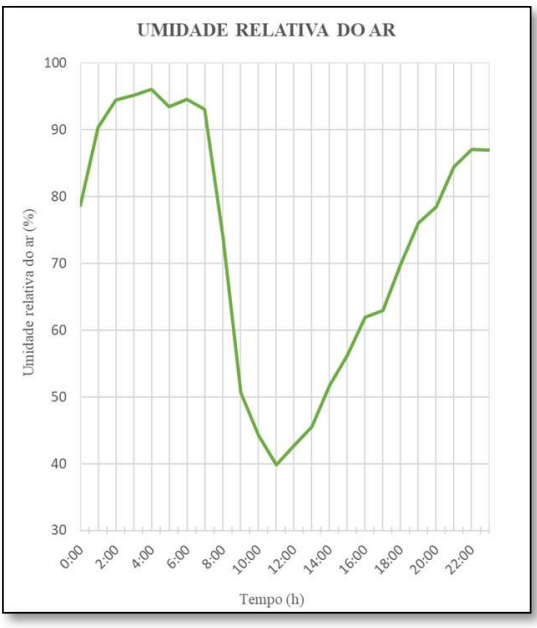

C

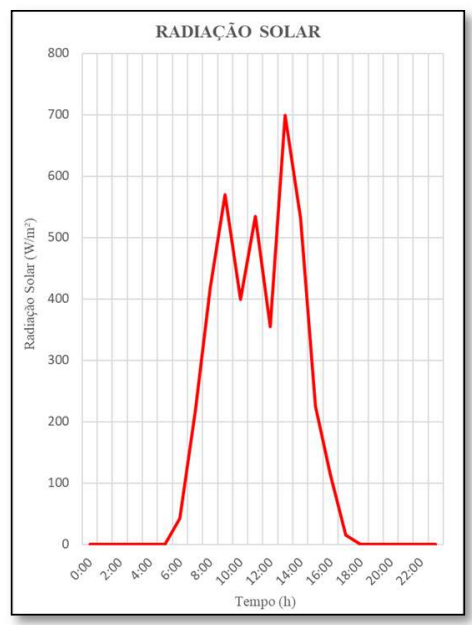

Figura 5: A: Temperaturas internas do ar/ B: Umidade relativa do ar/C: Radiação solar (04/09/2015).

Os resultados das temperaturas internas são apresentados na Figura 6. O gráfico dessa figura A mostra as temperaturas internas do ar. Nele se observa que durante as primeiras horas do dia as temperaturas externas são mais baixas (às 8h), o comportamento de todas as células de teste se apresenta 
bastante aproximado, destacando como a mais baixa a temperatura a da CC $\left(16,5^{\circ} \mathrm{C}\right)$ e a mais elevada a da célula CV $\left(17,2^{\circ} \mathrm{C}\right)$. No período vespertino, quando a temperatura externa atinge seu valor máximo $\left(28,3^{\circ} \mathrm{C}\right.$ ás14h), existe uma diferença de $2,5^{\circ} \mathrm{C}$ entre as temperaturas internas do ar da $\mathrm{CC}\left(25,5^{\circ} \mathrm{C}\right.$ às $\left.17 \mathrm{~h}\right)$ e da CVFV $\left(23^{\circ} \mathrm{C}\right.$ às $\left.17 \mathrm{~h}\right)$. A célula de teste CVFV apresentou a maior atenuação da temperatura com relação à externa $\left(5,3^{\circ} \mathrm{C}\right)$.
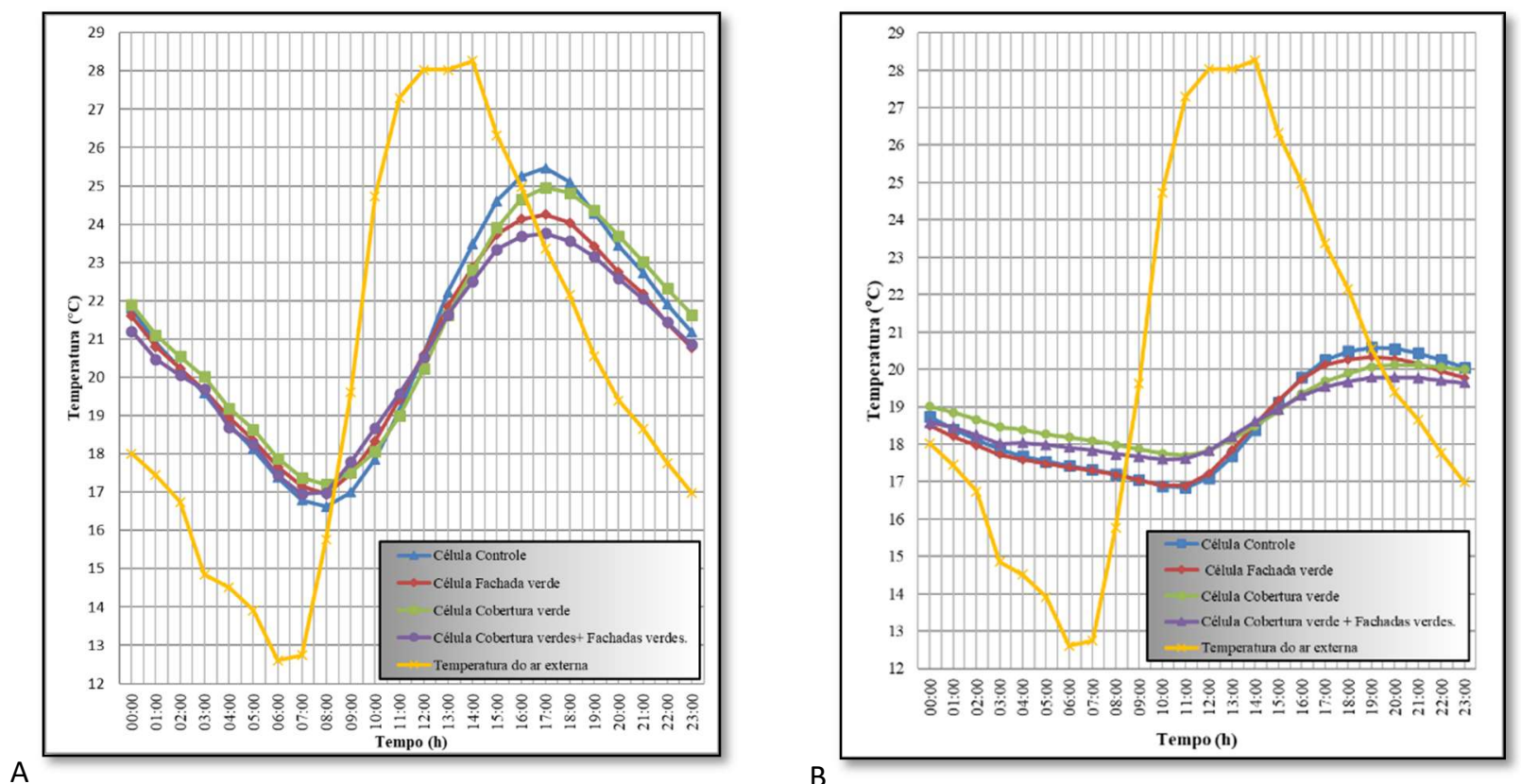

Figura 6: A: Temperaturas internas do ar/ B: Temperaturas superficiais das coberturas (04/09/2015).

No mesmo período, as células CV e FV registraram uma temperatura do ar de $25^{\circ} \mathrm{C}$ e $24^{\circ} \mathrm{C}$ respetivamente, ou seja, uma diferença de $0,5^{\circ} \mathrm{C}$ e $1^{\circ} \mathrm{C}$ com respeito a $\mathrm{CC}$. $\mathrm{O}$ atraso térmico de todas às células de teste foi de $3 \mathrm{~h}$. O gráfico B da Figura 06 representa as temperaturas superficiais internas. No período matutino, quando as temperaturas mais baixas do dia são registradas, existe uma diferença perceptível entre as temperaturas superficiais das células. A CC e a FV apresentam um comportamento idêntico e uma temperatura mínima de $17^{\circ} \mathrm{C}$ às $11 \mathrm{~h}$, sendo importante destacar que ambas possuem telhados cerâmicos, enquanto, as células equipadas com coberturas verdes, CV e CVFV, registraram uma diferença de temperatura superficial de $2^{\circ} \mathrm{C}$ com respeito das anteriores.

No período da tarde, a maior diferença de temperatura superficial registrou-se entre as células CC e CVFV com um valor de $1^{\circ} \mathrm{C}$, entre as células restantes a discrepância foi aproximadamente de $0,5^{\circ} \mathrm{C}$. Dessa forma é notória a que a Célula que apresenta cobertura e telhado verde comporta-se de maneira a permitir, ao menos do ponto de vista quantitativo, melhor conforto térmico, do que a Célula que não recebeu nenhum elemento vegetal para atenuação térmica. Esses resultados também podem contribuir para questões energéticas, ligadas ao controle artificial da temperatura dos elementos construtivos, por meio de eletrodomésticos.

\section{CONCLUSÕES}

Nas horas do dia mais frias, no período matutino, as células que possuem vegetação apresentam as 
temperaturas mais altas e no período do dia mais quente, vespertino, registram as temperaturas mais baixas, ou seja, as variações de temperaturas (amplitudes térmicas) são menores, o que significa um comportamento mais constante e temperaturas mais atenuadas.

Deste modo, confirma-se que o uso de vegetação ameniza as temperaturas internas das edificações nas que foi implantada. Esta redução de temperatura pode ter consequências positivas para os usuários, tal como no sentido térmico, bem como se pode ter no sentido econômico, uma vez que, está diretamente relacionado com o consumo de energia e eficiência energética das edificações.

\section{REFERÊNCIAS}

ABNT. Associação Brasileira de Normas Técnicas. NBR15575: desempenho térmico de edificações. Parte 1edifícios habitacionais de até cinco pavimentos. Rio de Janeiro: ABNT, 2013.

DINSDALE, S.; PEAREN, B.; WILSON, C.. Feasibility study for green roof application on queen's university campus. Kingston: Queen's Physical Plant Services, 2006.

DUNNETT, N.; KINGSBURY, N.. Influence of vegetation composition on runoff in two simulated green roof experiments. Urban Ecosyst, v.11, n.4, p.385-398, 2008 a. DOI: http://doi.org/10.5194/piahs-364-538-2014

GALLARDO, N. P.. Resposta térmica de edificações com envolventes vegetais: coberturas verdes e fachadas verdes. Tese (Doutorado em Ciências da Engenharia Ambiental) Universidade de São Paulo, São Carlos, 2017.

GALLARDO, N. P.; NEVES, Z. F. G.; SANCHES, M. S.; RORIZ, V.
F.; TECH, A. B. R.; VECCHIA, F.. Thermal response to cold in buildings with green covers for tropical climate; green facades and green roofs. International Journal of Current Advanced Research, v.6, p.2768-2775, 2017. DOI: http://doi.org/10.24327/ijcar.2017.2775.0101

NICODEMO, M. L. F.; PRIMAVESI, O.. Por que manter árvores na área urbana?. São Carlos: Embrapa Pecuária Sudeste, 2009.

PECK, S.; CALLAGHAN, C.; KUHN, M.; BASS, B.. Greenbacks for Green Roofs: Forging a New Industry in Canada. Status Report on Benefits, Barriers and Opportunities to Green Roof and Vertical Garden Technology Diffusion. Canada: Canada Mortgage and Housing Corporation, 1999.

ZAKIA P. R.. A influência da vegetação no conforto térmico do ambiente construído. Dissertação (Mestrado em Engenharia Civil) - Universidade Estadual de Campinas, Campinas, 2004.

A CBPC - Companhia Brasileira de Produção Científica (CNPJ: 11.221.422/0001-03) detém os direitos materiais desta publicação. Os direitos referem-se à publicação do trabalho em qualquer parte do mundo, incluindo os direitos às renovações, expansões e disseminações da contribuição, bem como outros direitos subsidiários. Todos os trabalhos publicados eletronicamente poderão posteriormente ser publicados em coletâneas impressas sob coordenação da Sapientiae Publishing, da Companhia Brasileira de Produção Científica e seus parceiros autorizados. Os (as) autores (as) preservam os direitos autorais, mas não têm permissão para a publicação da contribuição em outro meio, impresso ou digital, em português ou em tradução. 